\title{
Cross-line Of East And West: Second Generation Pakistani Youth In Norway
}

\author{
Anwar Muhammad \\ Development Studies Programme \\ Iqra University, Islamabad
}

\begin{abstract}
Pakistani community constitutes the largest group of immigrant population in Norway and its second and third generation youth has a predominated majority in the Pakistani immigrant population in Norway. This generation, which has grown out of the Norway-born-and-bread single parent and then both parents, is different in every aspect from that of their parents or first generation: they are more exposed to and aware of the Norwegian culture. And they are better equipped to safeguard and promote their interests. At the same time, they are also familiar with their parents' culture and values. Gender issues are often in focus of the media coverage dedicated to the immigrant community in the context of traditional gender role in Pakistani society. This paper focuses on the notion of second generation, identity work and gender. Gender is the cross-cutting theme throughout this paper. This paper deals with theoretical discussion on second generation youth in Norway. It also co-relates the findings of a qualitative study by using the theoretical models and presents some recommendations based on this study.
\end{abstract}

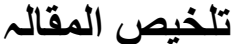

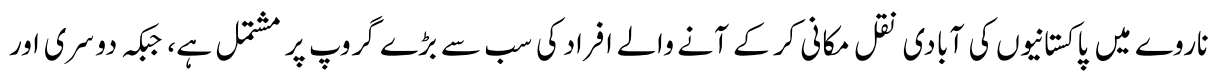

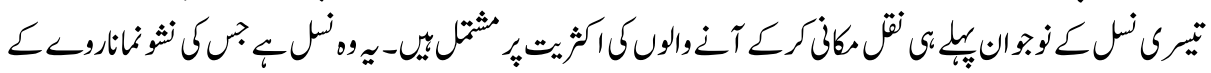

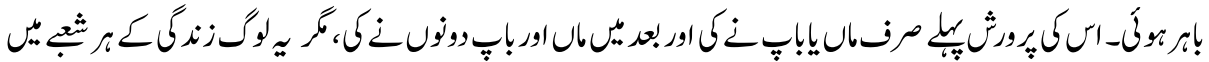

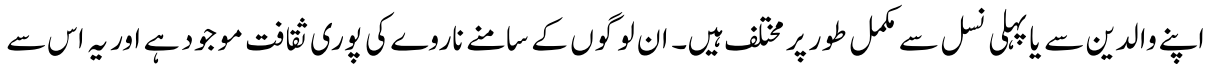

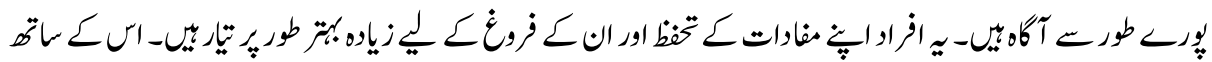

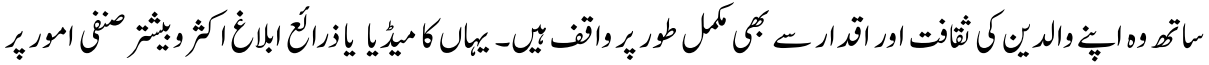

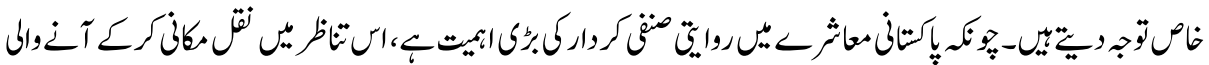

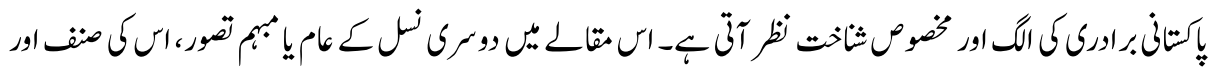

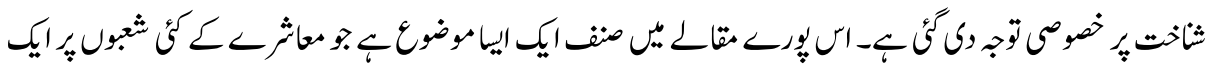

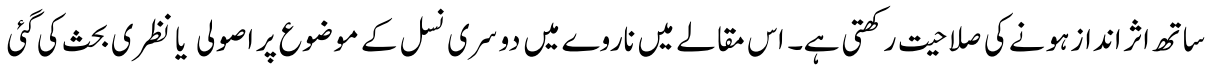

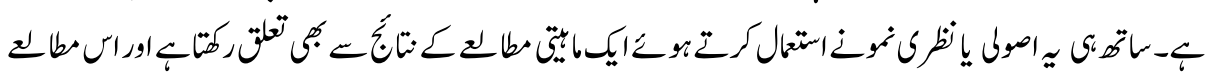

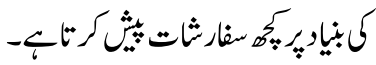




\section{Background}

First Pakistanis to arrive in Norway, after the country opened up its labour markets for foreign workers, was a group of ten men, who landed in Oslo in 1967. They were close kin of the families that had settled either in Denmark or Britain (Ahlberg, 1990). Since then, the number of Pakistani community has grown steadily and consistently. Now they constitute the largest group of the second generation within the Norwegian immigrant population, which, as of July 1,2007 , was 8.3 per cent $(45,776)^{1}$ of the country's total population of 4.7 million. The growth has generally come, especially after Norway imposed a total ban on hiring workers from foreign counties, in 1975, through family expansions and reunions.

The demography of Pakistani immigrant population until then had a male predomination. Not a single woman from Pakistan was a resident in Norway. But it was not later that the trend changed. And the number of dependents increased by 601 women to 177 men between 1976 and 1981 (Ahlberg, 1990).

The pattern followed by the Pakistanis migrating to Norway was similar to that of their countrymen migrating to other European countries: they migrated in a chain system. The geographical concentration was also witnessed among the migrating population. An overwhelming majority of them came from Tehsil, Kharian of the district Gujrat of Punjab - the central province of Pakistan which has the majority of Punjabi ${ }^{2}$ speaking population. Pakistanis from other cities also came to Norway, but their number was not as significant as of those from Gujrat.

Although, a hope for better economic opportunities and prosperous life brought the Pakistanis in large numbers to Norway, they quickly realized they would have to face twofold challenges to integrate into the local culture, and at the same time to remain loyal to and expressing their religious, cultural and patriotic beliefs and values. While they worked and lived in Norway, their hearts and minds were in Pakistan. The challenge became even greater when they tried to implement here the same traditionally conservative family structure they were used to in Pakistan; where men predominantly rule the whole family and role of women is limited to that of housewives.

This family structure is derived from the class system that is in practice in central and southern parts of Pakistan (Awan 1980, Ahlberg, 1990). The system has a major influence on family and community decision-making processes. Mainly, it is run through a Biraderi ${ }^{3}$ system, based on a clan style kinship. Family is headed by a male member, and thus is patriarchal in nature. The Biraderi complements the strengthening of patriarchal structure within the family and the wider kinship network. Furthermore, the rural urban and ethnic differentiation makes a major difference in their living, socialization and also inter-community communication (Chauhdry 1987). Pakistanis 
carried and attempted to implement these attitudes in different countries they migrated to. This includes Norway.

\section{Integration, Media Images and Gender}

The second and third generation youth has a predominated majority in the Pakistani immigrant population in Norway. This generation, which has grown out of Norway-bornand-bread single parent and then both parents, in every aspect is different from that of their parents or first generation: they are more exposed to and aware of the Norwegian culture. And they are better equipped to safeguard and promote their interests. At the same time, they are also familiar with their parents' culture and values.

A lot of research studies (Østberg 1998, 2003a, 2003b, Andersson 2000, 2005a, 2005b, Bredal 2005, Jacobsen 2005a, 2005b) indicate that many of this generation want to get the best of both the worlds: they want to attain personal freedom and to be treated as equals to indigenous people. But at the same time they have a sense of belonging to and security in their parents' culture. Therefore many often end up living two lives: their parents' traditional conservative life at home and the Western one outside. They continue to be practising Muslims, speak Punjabi and follow customary traditions such as participation in birth-day, marriages, funerals and religious festivals.

Due to their exposure to and openness to both cultures, they sometimes gain but more often lose best of both the worlds. On one hand, because of the loyalty to their parents' culture and religious beliefs and values and an open expression of it, they are not accepted by the indigenous population as Norwegian: they are still considered as outsiders who will one day go back to Pakistan. On the other hand, they are often seen and accused, by their parents, of becoming 'too Norwegian'.

While the former phenomenon has made the integration of this generation into local culture and society more difficult for them, the latter has led to a generation gap in the Norwegian Pakistani community. As a result, many questions are confronting the young generation to think and move forward. As a result, the young generation is confronted with many difficulties as regards the necessity to think. They include: how is it to live in and survive the two cultures? What are the problems they have to cope with? Is the generation gap too wide to be filled?

It is pertinent to analyze the role of Norwegian media here. By and large the media coverage of the immigrant community, for one reason or another, tends to be negative. They often define the youth through stereotyping and negative references. Most of the time, this is facilitated by the provocative outbursts of the politicians. In reality young people have made positive contributions to Norwegian society. They are politicians, debaters, writers, medical students, and journalists. Again, while a few research studies 
have focused on their political, social and economic contribution mentioning those positive aspects of Paki presence in Norway are rarely highlighted by the media and politicians.

Gender issues are often in focus of media coverage dedicated to the immigrant community in the context of traditional gender role in Pakistani society. It is ensured that Pakistani women rarely migrated alone for economic or other reasons. Therefore, their migration is linked organically with the migration of their male kin.

Issues such as forced marriages are a matter of concern for the government, Pakistani community itself and Norwegian society in general. But the exaggeration made by the media creates an artificial challenge for the community. As in many cases youth in their contact with other ethnic communities will be defending their position regarding forced marriages (Østberg 2003a, 2003b). The real problematic situation, which has been less explored, is the cases of marriage breakdowns: women are often abandoned and find it difficult to get divorced. Furthermore, they are socially excluded from the community.

Recent work (Cohen 1999, Jawad 2003, Jacobsen 2005a, 2005b) shows that complex overlapping of historical, political, social and economic factors contribute to the disadvantaged position of Muslim women in the West. Tension arises for Muslim and non-Muslim communities when ignorance and division of groups prevent mutual understanding.

This paper focuses on the notion of second generation, identity work and gender. Gender is the cross-cutting theme throughout this study. To put this situational context into the theoretical and conceptual framework, the next part of the paper deals with theoretical framework, research objectives, questions and rationale of the study.

\section{Concepts and Framework; Identity work, Plural identities and Cultural hybridity}

On issues related to Pakistani immigrants in Norway there have been many research studies in Norwegian and English languages. Most of them have focused on the religious, health and sports issues faced by the community. Socialization, integration and identity work questions have been thoroughly discussed by academia, politicians and media in general.

Research on Pakistani community has generally been carried out by the Norwegians. Very few Pakistani researchers (Awan 1980, Daud 19888, Islam 1990, Anwar 1996) have done research on this issue. This mix of research studies presents its own dynamics. They have their own strengths and weaknesses.

As Liebkind (1989) points out, disentangling this complexity is challenging, since "it is a frequently repeated contention that the social and behavioral sciences dealing with 
identity, inter-group relations, ethnic or cultural minorities and related phenomena overflows with theories, concepts and descriptive terminologies which may be incompatible with each other."

As rightly pointed out in the 'Cultural complexity in the new Norway: Strategic university programme, University of Oslo 2004-2009', "most research on minority/majority relationships in Norway has so far been strongly influenced by normative concerns reflecting the wish among the domestic authorities to "integrate" immigrants."

In the social sciences, particularly in sociology, integration theory has been used by many sociologists by combining micro- and macro-level theories to provide a comprehensive understanding of human social behavior. The integration theory is particularly useful for explaining social phenomenon because it shows how the different components of social life work together to influence society and behavior.

The phenomena of Integration is highly debated in the Norwegian society as pointed out by Eriksen:

"For one can be socially integrated in certain respects and not in others: The children of Pakistani immigrants in Oslo, for example, are integrated in the Norwegian educational system, but experience great difficulties in getting jobs afterwards (Eriksen: 2006)."

Integration implies both the preservation of, and contact with the home culture, or the "country of origin," and an active involvement with the host culture, or the "country of settlement."

The notion of identity has been used recently both in social sciences and in political discourse with a number of different meanings that were never properly defined. This systematic imprecision in itself constitutes an interesting mystery. However, in this research proposal I restrict myself to a limited discussion of this concept, which is directly associated with understanding cultural differences.

In sociology and political science, the notion of social identity implies individuals' labeling of themselves as members of particular groups - such as Nation (Pakistani), Ethnicity (Punjabi), Social class (Syed, Arian, Sujar, Kokhar) and so forth (Anwar 1979).

The concepts of 'self' and 'others' plays an important role in understanding identity negotiations. Furthermore, gender and identity are inter-related in many senses as Connell (2002) pointed out: 'bodily differences and social effects are often linked to the idea of character dichotomy. Women are supposed to have one set of traits, men another.' 
As mentioned earlier, gender concerns are addressed differently in Pakistani community. Traditional structure of the family and community has a major influence on gender roles and responsibilities. Priority to boys over girls in different sphere of life is one prominent area. This makes gender issues a central point in the study as it comes throughout the findings.

In general and particularly in case of Pakistani community, many people feel pride in their identity groups, which furthers a sense of community and belonging. Often they attempt to add to their identity by behaving in certain ways.

In the process of making their own identity, youth and people in general keep creating their identity as a self in relation to others. This process can be considered as 'identity work' whereby individuals aim to incorporate the different aspects of two or multiple cultures in his or her self conceptions. Andersson (2005b: 35) has defined identity work as the 'ongoing process of adaptation to diverse social demands, of reflections on categorical identities and on one's own normative standards.'

The concept of 'integrated plural identity' was used in the first study 'Pakistani Children in Oslo: Islamic Nurture in a Secular Context' by Østberg (1998) to express the dual character of Norwegian-Pakistani children's identity. The notion of integrated plural identity implies that negotiations are done at various levels starting from parents to siblings and within peer groups. As Østberg (2003b:164) points out 'negotiations are also going on within each individual, in the form of reflexivity, compromises, creativity and the management of plural identities'.

Concerning the condition of second-generation immigrants/youth in Europe, there are two main clusters of approaches and conclusions in the growing international research literature (this also applies to Norway). Among these, the most recent is that these young people are seen to be in a specific position as regards cultural productivity and creativity. In most of the earlier studies in Norway on this topic, it appears that the situation of second generation youth is vulnerable. This literature presents a picture of the youth as being 'in-between-two-cultures' (Daud 1988, Islam 1990, Østberg 1998, Andersson 2000).

In the last two decades, immigrant youth have often been held up as the grant (empirical) examples illustrating the more general theories about the diaspora and cultural hybridity as enriching positions. This orientation which is often referred to as 'cultural hybridity' approach has in large measure developed as counter-reaction to the other and earlier dominant 'in-between-two-cultures' approach. Whereas the 'cultural hybridity' ${ }^{6}$ approach tends to focus on the positive and emancipatory aspects that exist in the migrants youth status, the other approach focuses on the negative aspects of self-identity, of being forced to be 'in-between-two-cultures'. 
At both theoretical and methodological levels, this paper has been influenced by the work of Østberg (1998, 2003a, 2003b) Andersson (2000, 2005a, 2005b) on identity work and socialization of second generation Pakistani youth in Norway. In this study, diversified 'analytical tools' are used to interpret empirical data. The analytical tools were chosen because of the nature of the study.

In this paper, I will to a large extent present a picture of the youth as competent cultural navigators, not trapped between two cultures but moving easily in a complex cultural and social context and negotiating their own identity. On the other hand, I will show that many of them also struggle with defining themselves in relation to others, and that many have or have had conflicts with family members from the older generation. Both perspectives may therefore have something to offer as explanatory models in relation to my data material.

Research Questions of the Study: The main research questions of the thesis are:

1. How are the second generation Pakistani youth integrating into Norwegian society?

2. How does gender play a role in identity work and in the integration process and to what extent are gender and identity problems occurring?

In my interview guide, these two questions were further divided into sub-questions addressing issues around gender, identity work, integration, second generation youth, and gendered organizations.

Methodology: Keeping the nature of the research, qualitative method was mainly used for data collection in order to capture the topic from different social and academic aspects. Different instruments and tools were used to answer the validity and reliability of the material. Focusing on two main research questions and three objectives in view, an interview guideline was prepared which had different thematic focuses in order to capture the Norwegian Pakistani youth life experiences of integration and identity work. Gender was a cross-cutting theme throughout the sections of interview guide.

This research was exploratory in nature, thus based on questions instead of setting hypothesis and testing. Below are the further specification of research tools and instruments and how they were applied in field work. The diverse tools for data collection complemented each other and helped improving the reliability of my findings. In-depth interviews were the main tool for the collection of information whereas other techniques supplemented the findings of in-depth interviews. The other tools include literature review, focus group discussions (FGD), expert interviews, participant observations, case studies and best practices, sharing of findings, revision and improvisation. 
Challenges and Ethical Problems: There were many challenges and ethical problems encountered during the process of field work, but here only related to gender are included in this paper.

Gender Considerations: The Pakistani community in Norway has strong rural, urban and class system biases and preferences. For this study I included everyone without disclosing information about other respondents which made an impression to them that their own privacy will also be taken care of.

Being male student interviewing Norwegian Pakistani girls was also one of the complicated areas for my field work as it could have a negative impact on the process of field work and interviewing Pakistani community in general. For this matter, as a preventive strategy, dress code was chosen carefully while meeting Pakistani community people and very soft and well mannered language (in most of the cases Urdu) was spoken with these fellows to leave a good impression about me. My working experience of Aga Khan Foundation in Pakistan and journalism background was also helpful in making a good base for my own reputation.

Going Back Home: Re-shifting Focus: This section focuses on the notion of integration and plural identity and its complex dimensions. Capturing youth's day-to-day experiences in the society, it reflects their process of integration and identity work and goes on for the negotiation of identity. Following the nature of the interview guideline, this section depicts findings in the thematic areas, instead of presenting them as general findings and keep view the fact that in identity has been defined in many ways in social sciences. In sociological terms, identity is a dynamic process of feeling the self in interaction with immediate others, an experience of being and belonging which continues throughout the life span of a person (self). Question of identity is one of the crucial components for this paper, which is also the departure point for the demystification of identity work. Here, we may refer to the definition of identity work provided by Anderson (2005b:35).

According to him it is 'on-going process of adaptation to diverse social demands, of reflection on categorical identities and on one's own normative standards'. This applies in case of my research findings as well, as it is obvious from the diverse and complex nature of inter-related issues raised in the coming sections. Keeping the nature of the subject and interview guideline the following sections have derived from the analysis of the findings. As part of the analysis and sharing with experts these sections were further refined and completed in the current order.

Perspective of Integration: Some Examples: In terms of identity and belonging, Norwegian Pakistani youth feel prouder to introduce themselves as Norwegian rather than Pakistani after being grown-up in Norway and having been to Pakistan (summer 
holidays, family marriages/events or formal or religious education) many times they feel more strongly associated with Norway (without any external or internal pressure) as their visits to Pakistan play an instrumental role in their shifting of identities.

In very rare cases, there are some young people who have strong feeling of good integration in Norway and expect the Norwegians to get integrated further to foreign culture i.e. Pakistani. Quoting different kinds of integration examples, these people feel well adjusted in the society and consider that other segments of society are fragmented which creates some kind of problems for other nations to integrate. Such views were reflected in one of the interview when Saqib said:

'This is time for the Norwegian's to integrate with Pakistani family system and values. They do not have a family system. I am 26 , but still live with my parents, born and brought up in Norway but have no major problem while living with them, whereas majority of the Norwegians will not do as I am doing. The Pakistani community has brought many changes in Oslo and its surrounding areas i.e. dressing, eating and late opening hours for shops. Though, on the contrary, it has also changed because of the local culture i.e. skiing, hiking and swimming, as I never learnt and did them but my nephew and nieces do them regularly from their childhood.'

It was interesting that Saqib was pointing at the notion of 'integrated plural identity', earlier raised by Østberg $(2003 a, 2003 b)$ in her research work. In the concept of plural identity, more identities are hidden. With excitement and pride he was sharing and reemphasizing how Pakistani community has influenced Norwegian society. Interestingly, his fluid and changing identical? perceptions were contradictory as he said:

I was born and grown up in Norway, I was like them (Norwegians). I was used to consider myself among one of them but after a long time, I realized that I do not belong here, my roots are somewhere else (Pakistan). Acceptance from heart is not there for second generation youth like me by the Norwegians, though on paper we are considered as them but we are not alike. Though it is a fact that the second generation is more considerate to the local values and system whereas first generation people are more concerned with things related to back home.'

Later in the discussion, when he was asked if he has the intention of settling down in Pakistan as his roots are there, he suddenly changed his position and stated that he is Norwegian as he has been grown up in Norway. On the level of living standard and societal infrastructure, he is impressed by the Norwegian system, while he has a negative impression about Pakistan as experienced by himself. 
Lack of education and awareness among first generation people is one of the key factors for creating problems at different levels. You can take all different kind of issues and ultimately they will be connected to illiteracy or lack of understanding. As most of the first generation people came from the rural areas of Pakistani with little education and exposure to the urban life in Pakistan. Since sudden exposure to Norwegian society was a totally shocking experience of life, they became more protective of their religion and social values while being in Norway. Though the same family values have been changing in Pakistan, but in Norway they live with the same values which the valued when they moved to Norway. This lack of understanding creates a problematic state once children (especially girls) grow up and face issues related to their own life. This can be further reflected in the case of Zara:

'Since the death of my mother, I am completely out of touch with my family members in Norway. It was my mother playing the bridging role in family and taking care of us. As a kid I was always reminded that I am different from others (Norwegians) in my origin, language accent, color, and dressing. Grown up in a very conservative and typical controlled environment of Pakistan while living in one of the big cities of Norway, I could not resist in my childhood but later on during the high-school time, I started resisting and raising my voice about the restrictions i.e. late staying in evening, not meeting or talking to boys (either Pakistani or Norwegians), wearing proper dresses, not talking loudly. This was never appreciated and was the cause of tension in home as my younger sister also started following my trend.'

Zara, after completing her studies, has lived an independent life with her partner (ethnic Norwegian) and hardly speaks to her family members. She did not inform them about her partner as they will not easily approve of their relationship. In order to live up to the norms and standards of Norwegian society, she gradually started to reject her Pakistani self by changing her dressing, eating, socializing habits. Living in another city of Norway than the one where she grow up, she does not interact with the Pakistani community at all and hardly anyone knows about her. Thus she feels arguably more secure and independent.

Zara's case shows that both the in-between-two-cultures and cultural hybridity approaches can be used as models of interpretation. Generational conflicts and tensions are evident in this case, particularly when she was still dominated by her parents ("in between two-cultures"). In later years, she found her own of doing things and managed to free herself from the domination and incorporate elements from Norwegian culture in her ways of being. Instead of negotiation, she preferred an escape or a break from the family, however maintaining her own self as prime focus of her identity work. 
Going Back Home: Re-shifting focus: Parent's ideological identification with Pakistan has an influence on children with regard to their socialization process at family and community levels. While living in Pakistan children are presented a very idealistic picture of Pakistan and unconsciously they associate themselves with Pakistan. However ultimately they find their own roots in Norway instead of Pakistan. This was shared by many respondents. For example Sajid said:

'I was communicated a very constructive and idealist picture of Pakistan since my childhood. In most of the examples, Pakistan, its society and value system were presented constantly as role model to be followed by us. I visited Pakistan twice during the last five years for family reasons and after getting first hand experiences of Pakistan and it has broadened my understanding of the context. Now my family cannot quote and repeat the same examples, as I do not buy them anymore, I guess things have changed rapidly in Pakistan, it is not any more the same country as it used to be when my parents moved to Norway. What my parents quote and what really is there in Pakistan are totally contrasting and contradictory. It is possible that there might be a few things similar, but the majority of the social values has changed.'

This narrative of Sajid is one of the many stories of people who have similar views to share about their experiences to Pakistan as pulling the trigger by parents as they are the one who decide about visiting Pakistan and who should join them. One such turning point was for Noreen, 24, when she started associating herself with the Muslim identity as a substitute to Pakistani identity. She said:

'Being born and brought up in Norway (with little relaxation i.e. freedom to wear dresses of my choice, making friends), I was always taught that my roots are from Pakistan, that is my home country. Being a youth with less exposure to Pakistan, I was used to be proud to have Pakistani roots. In my childhood, I went to Pakistan many times. Since I turned 18, I went thrice to Pakistan. In Norway, my dressing was tshirt, kurta $^{7}$ and jeans but lately I myself started wearing hijab ${ }^{8}$ when I reached 21. Two years ago, I had gone to Gujrat, Pakistan to attend few family marriages. In one of the events, I was wearing traditional Pakistani dresses with hijab and a few people in the wedding started calling me sister of Osama bin Laden and terrorist as most of them were surprised that being from Norway I was wearing hijab instead of some modern European dresses. In the whole wedding, I was the only one who was wearing it. Then the following questions came to my mind: Is it Pakistan? Is it an Islamic country? Is it the same country which makes my parents proud? What am I doing here in such a kind of crowd? These and a few other experiences during that visit changed 
my whole paradigm of identity. Now I feel proud to associate myself with Muslim identity rather than Pakistani identity.'

Observing her carefully while she was sharing this experience, it was obvious from her body language and expressions that she was feeling uncomfortable and emotionally upset while she was narrating the above experience. It was obvious that she had high expectations for Pakistan and was regarding it as a role model, and her dreams were shattered in Pakistan by her own family or community members. Now she is skeptical about visiting Pakistan. Instead she prefers to visit Scandinavia or United Kingdom to see family relatives as they can understand her cultural up-brining in a multi-cultural context.

Cultural complexity in Pakistan and changing value system has drastically impacted on the diaspora as all of them consider Pakistan an ideal social society. Experiences, like Noreen's, reflect positively on identity work. This is a clear example where a youth rejects a position of being trapped in-between-two-cultures. She prefers to identify herself with one culture i.e. Norwegian, culture or in very few cases Muslim culture instead of Pakistani culture. It is one of the crucial points in the identity work when they suffer bad cultural experiences in Pakistan and look for alternatives to associate themselves with.

The way youth in Norway have been informed about Pakistan by their parents and family members leave long lasting idealist impressions of perfection, but they get disappointed when they see a totally different world. One such remarkable experience was shared by Zahida (35), one of the community leaders in Oslo:

'From the beginning, I attempted to educate my two daughters (one 17 and second 14) about Pakistani and Islamic values in Norway and went to Lahore, Pakistan with them first time last year. In Norway, they completed their religious education. They are studying formal education, wear shalwar kameez ${ }^{9}$ and on few occasions jeans, have few ethnic Norwegians as friends and are more obedient. During the visit first time, as their mother I was feeling bad, as something was missing in their socialization in Norway. On every bad experience they encountered it Pakistan, they asked: is it your Pakistan? This is what you call Islamic country? This is what you have been mentioning to us for a long time? Now Pakistani society has changed and has lost its traditional values and strengths. My daughters had firmly communicated that it was their first and last visit to Pakistan. I could not argue with them on this as I was not having anything in defense of my argumentation. In Lahore, they met many girls wearing jeans, $t$ shirts, staying out till late night with their friends (boys and girls) and few of them even had boyfriends. My daughters were feeling outclass. Being from Norway, they were more traditional while traditional people were more modern.' 
For Zahida's children, the 'Pakistani' identity and roots have no value and meaning. After going to Pakistan they prefer to call themselves 'Norwegian'. Most of the teenagers like them are gradually changing their perception about Pakistan and the way they associate themselves with Norway. Being a community leader and socially active person, Zahida is a role model, as many Pakistani women consult her for their personal and social issues. Now that she feels more confident, it is good that her children have decided about their identity at an early stage, and they will not be lost in different cultural expectations.

One may point out here that all the respondents had gone to Pakistan many times except a few who had gone only once or twice. In three cases, the whole family had gone to Pakistan and settled down for two to three years and then came back to Norway. The motivation for going to Pakistan for such a long time was that they considered the living environment in Oslo to be unsafe for boys. As a preemptive step, the whole family moved to Pakistan so that their boys could be educated there. The families had been concerned that the boys should not get engaged with criminal gangs or the so-called religious organizations in the early stage of their teenage as these organizations may seem very attractive to them.

From a gender relations perspective, visits to Pakistan have different impact and consequences on boys and girls for shifting identity work differently. In the case of boys, it is more future oriented or materialistic in nature, whereas for the girls, it is mostly understanding of family relationship, images of Pakistan and Islam. Nasar (22), young and single male exemplified the first tendency. He said:

'I do not see any future and career in Pakistan for myself. Socially I can not adjust in Pakistani society as I have spent most of my life in Norway. Though I visited Pakistan few times, yet I am more Norwegian Pakistani in my thinking than a Pakistani. People in Pakistan treat me differently as I am one of the "abroad born confused desi (ABCD)" for them. Educationally and economically I do not see any optimism in Pakistan, whereas in Norway at least I will not be having living or financial problems.'

Nasar was confident that his future is secure in Norway whereas in case of Pakistan he saw it as an unclear path. In the later part of the interview, he expressed his appreciation of the welfare system through which unemployed people receive support from the state. But future prospects seems more open in Norway though studies and gaining experience is time investing but worth doing so.

In the case of girls, short-term living experiences in Pakistan help them to understand the complex nature of family system in Pakistan, something which plays a major role in planning a future for them. Simran (23) says: 


\begin{abstract}
'Once I was in Kharian Pakistan. I met most of my cousins and was able to understand them socially and psychologically. Though I was not interested in meeting them, but a situation was created and I had no other option. Later on, when the issue of my engagement came up, my family in Norway gradually started dropping names for my choice. I rejected all of them on medical reasons as it is not good to marry firstcousin after one of my cousins from Pakistan got married to another of my cousins living in UK.
\end{abstract}

While sharing this experience, her tone and body language showed that she had sympathy for her cousin from the UK who had to get married to another cousin in Pakistan and she could not convince her family like Simran. In many ways, Simran is one of the very few Norwegian Pakistani girls who had the courage to stand and fight for her own choice. Many of them could not resist for long in-front of family pressure. Simran's case is a good example of integrated youth; knowing her rights, having freedom of expression and standing for it. Rejecting her parent's decision and will, she left good sign for other girls as to how to resist against the family system and decisions.

Going back to the first generation people is experiences in Norway, it is important to know as to why they did not prefer Norwegian identity for their children. It is an interesting and complex turning point. If it is considered seriously, it will reduce the generational conflicts. However, there is no single explanation to explain as to why people are not integrated after living for so long.

During the process of field work, while talking to many youth, only one regarded herself as primarily a Norwegian. Having association with Norway and calling themselves primarily as Norwegian are the changing trend among youth which is a positive sign for their integration. Most of the youth change their associations after visiting Pakistan once or twice in their life time.

Different cases in this paper clearly show that the cultural hybridity approach is a fruitful one: the youth aim at being integrated in the Norwegian society, and at the same time retain some identification with the culture of their parents. This also provides a reflection on the in-between-two-cultures experiences. Different examples of integration i.e. Saqib's, Zara's, or Noreen's carry their own complexity. Sometimes, in extreme cases, they also opt for other identities like Muslim and rarely Pakistani identity. They however, also reject a lot of what they consider to be bad in Norwegian society. In the light of the observations placed above, the following recommendations may he offered:

1. An openness towards and acceptance of the youth's wishes and choices by the first generation Pakistanis in Norway; 
2. Holistic and systematic efforts at national level to bridge the gap between the first and second generations;

3. A focus on gender equality at household level, providing girls with equal opportunities. The role of the state is crucial here;

4. A positive portrayal by the media i.e. neutral reporting. Plus political inclusiveness of youth by ethnic politicians;

5. More inclusive approaches for the integration of immigrants, particularly of the second generation youth;

6. More research dealing with issues such as: a) First and second generation integration dynamics; b) Youth's integration experiences in other cities comparative analysis; c) Influence of media reporting on identity work; d) Impact of $9 / 11,7 / 7$ or recent debate about terrorism and youth participation; and e) Comparative study of youth integration in Norway and Denmark.

\section{End Notes}

${ }^{1}$ http://www.ssb.no/befolkning_en/ accessed on July 29,2007 at 23:22

${ }^{2}$ One of the local languages of Pakistan, spoken mostly be the people of Punjab province.

${ }^{3}$ Biraderi, is an extra-familiar kin networks. Kinship is identified or viewed as Biraderi in Pakistani context.

${ }^{4}$ http://www.culcom.uio.no/programmet/programbeskrivelse-eng.html accessed on May 14, 2006 at 22:55 - Cultural complexity in the new Norway: Strategic university programme, University of Oslo 2004-2009

${ }^{5}$ Eriksen, Thomas Hylland,. Some analytical dimensions of cultural complexity, (version 0.9), http://www.culcom.uio.no/publikasjoner/THE-complexity.html

${ }^{6}$ Hybridity is a central term in post-structuralist cultural theory and in some variants of globalization theory. It is tied to the idea of cultural syncretism, rather than the cultural difference solidified by multiculturalism, in terms of the interpenetration of elements (Anthias 2001).

${ }^{7}$ Regular dress of Pakistan

${ }^{8}$ Veil

${ }^{9}$ Traditional dress for boys and girls, now more popularly common in rural areas.

\section{Bibliography}


Ahlberg, N. (1990). New challenges, old strategies : themes of variation and conflict among Pakistani Muslims in Norway. Helsinki,.

Andersson, M (2005b). Individualized and Collectivized Base for Migrant Youth Identity Work. in Sernhede, O. et al. (2005). Youth, otherness and the plural city: modes of belonging and social life. Göteborg, Daidalos.

Andersson, M. (2000). "All five fingers are not the same": identity work among ethnic minority youth in an urban Norwegian context. Bergen, Centre for Social Science Research, University of Bergen.

Andersson, M. (2005a). Urban multi-culture in Norway: identity formation among immigrant youth. Lewiston, N.Y., Edwin Mellen Press.

Anwar, M. (1979). The myth of return: Pakistanis in Britain. London, Heinemann.

Awan, M. D. (1988). Socialization of Pakistani children in Norway. Oslo, Universitetet.

Bø, B. P. (2002). Immigration control, law and morality: visa policies towards visitors and asylum seekers : an evaluation of the Norwegian visa policies within a legal and moral frame of reference. [Oslo] „, Unipub.

Brettell, C. B. (2003). Anthropology and migration : essays on transnationalism, ethnicity, and identity. Walnut Creek, Calif., AltaMira Press.

Brunvand, L. (1998). Migration, vitamin D and health : nutritional deficiencies in pregnant Pakistanis in Oslo and possible consequences for their infants. Oslo, Department of Pediatrics, Ullevål Hospital, University of Oslo.

Chauhdry, K. H. (1987). Dilemmas and compromise : the situation of Pakistani immigrants in Norway. Oslo, UiO/UISa.

Chow, R. (1998). Ethics after idealism : theory, culture, ethnicity, reading. Bloomington, Ind., Indiana University Press.

Cohen, J., M. Howard, et al. (1999). Is multiculturalism bad for women? Princeton, N.J., Princeton University Press.

Connell, R. W. (2005). Gender. Cambridge, Polity.

Fullinwider, R. K. (1996). Public education in a multicultural society : policy, theory, critique. Cambridge, Cambridge University Press.

Giri, A. K. (2002). Conversations and transformations: toward a new ethics of self and society. Lanham, Md., Lexington Books. 
Ireland, P. R. (2004). Becoming Europe: immigration, integration, and the welfare state. Pittsburgh, Pa., University of Pittsburgh Press.

Islam, R. U. (1990). Conflict between expectations and realities: a study of Pakistani children in Norway. Bergen, [R.U. Islam].

Jacobsen, C (2005b) Muslim GenDerations: Questions of Identity in 'the return to Islam'. in Sernhede, O. et al. (2005). Youth, otherness and the plural city: modes of belonging and social life. Göteborg, Daidalos.

Jacobsen, C.M. (2006). Staying on the Straight Path: Religious Identities and Practices among Young Muslims in Norway. PhD thesis submitted to the University of Bergen

Jacobsen, Christine (2005a), "The Quest for Authenticity: Islamization Amongest Muslim Youth in Norway," in Cesari Jocelyne and McLoughlin Sean (eds.) European Muslims and the Secular State, Ashgate, England

Jawad, H. A. Historical and Contemporary Perspectives of Muslim Women Living in the West, in Jawad, H. A. and T. Benn (2003). Muslim women in the United Kingdom and beyond elektronisk ressurs. Boston, MA, Brill.

Kvale, S. (2007). Inter Views: an introduction to qualitative research interviewing. London: Sage.

Liebkind, K Conceptual approaches to ethnic identity in Liebkind, K. and European Science Foundation (1989). New identities in Europe: immigrant ancestry and the ethnic identity of youth. Aldershot, Gower.

Line, Nyhagen Predelli (2004) Interpreting Gender in Islam: A case study of Immigrant Muslim Women in Oslo, Norway. in Gender and Society, Vol 18 (4): 473-493, Sociologists for Women in Society, London.

Mendieta, E. and L. M. Alcoff (2003). Identities: race, class, gender, and nationality. Malden, Mass., Blackwell.

Modood, T. and P. Werbner (1997). The Politics of multiculturalism in the new Europe : racism, identity and community. London, Zed Books.

Nagel, C. and G.-W. Falah (2005). Geographies of Muslim women: gender, religion, and space. New York, Guilford Press.

Østberg, S. (1998). Pakistani children in Oslo : Islamic nurture in a secular context. [Warwick], [University of Warwick]. 
Østberg, S. (2003a). Cultural diversity and citizenship: reflections on ethnicity, religion, nationhood and citizenship among Pakistani young people in Europe. in Jackson, R., G. Skeie, et al. (2003). International perspectives on citizenship, education and religious diversity. London, RoutledgeFalmer.

Østberg, S. (2003b). Norwegian-Pakistani adolescents: Negotiation religion, gender, ethnicity and social boundaries. in Nordic Journal of Youth Research, Vol 11 (2): 161-181, SAGE publications, London.

Parekh, B. (2006). Rethinking multiculturalism : cultural diversity and political theory. Basingstoke, Palgrave Macmillan.

Selikowitz, H.-S. (1987). Oral health and immigrants: a study of the oral health and oral health behavior in groups of Vietnamese refugees and Pakistani immigrants in Norway. Oslo, Universitetet.

Sernhede, O., M. Andersson, et al. (2005). Youth, otherness and the plural city: modes of belonging and social life. Göteborg, Daidalos.

Solomos, J. (2005). Race, ethnicity and social theory: John Solomos. London, Routledge.

Stanfield, J. H. and R. M. Dennis (1993). Race and ethnicity in research methods. Newbury Park, Calif., Sage.

Storhaug, H. and Human Rights Service (2003). Human visas: a report from the front lines of Europe's integration crisis. [Høvik], Kolofon.

Suhrke, I. (2001). Equal and different: politics of integration and Muslim requests for recognition in Norway. Bergen, [I.Suhrke].

Werbner, P. (1990). The migration process : capital, gifts and offerings among British Pakistanis. New York, Berg.

Werbner, P. (2002). Imagined diasporas among Manchester Muslims: the public performance of Pakistani transnational identity politics. Oxford, James Currey. 
Anwar Muhammad A first male Graduate of Women's Studies in Pakistan from Centre of Excellence for Women's Studies, University of Karachi. He is M.Phil in Gender and Development Studies from Norway, currently a visiting faculty at Iqra University's Development Studies Program, has more than eight years experience in the development sector of Pakistan in various capacities with leading organizations such as NGO Resource Centre (A project of Aga Khan Foundation), UNICEF, Marie Stopes Society, LEAD Pakistan, Four Corners Group.

* Acknowledgement: I am thankful to my supervisor and co-supervisor Dr Haldis Haukanes, Director, Gender and Development Studies Program, Department of Education and Health Promotion, Faculty of Psychology, University of Bergen, Bergen, Norway and Dr Sissel Østberg, Rector \& Associate Professor, Faculty of Education, Oslo University College, Oslo, Norway for their feedback and comments on this paper, which helped me in finalizing it. 